\title{
METODE TAHFIZH AL-QUR'AN \\ DI PONDOK PESANTREN MUHAMMADIYAH BOARDING SCHOOL KLATEN
}

\author{
Meti Fatimah \\ Fakultas Tarbiyah, Universitas Muhammadiyah Surakarta \\ Email: fatimahcan@gmail.com
}

\begin{abstract}
Until now, memorization is still one of the methods used in the process of maintaining the Koran. This research is related to the tahfizh al-Qur'an method which is more directed at the learning process at the Muhammadiyah Boarding School Klaten Islamic boarding school. The research aims to reveal descriptively the methods of learning khifdhul jaded and khifdhul coding in improving the quality and quantity of memorizing al-Qur'an of the students of the boarding school Muhammadiyah boarding school Klaten. This qualitative research is a research approach that produces descriptive data, which is written or oral data and observe people's behavior. The research data collection was carried out by means of observation, interviews, and documentation. Data analysis is a process of organizing data into patterns, categories and a basic description, so that a working hypothesis can be found and formulated. The first stage is data reduction, the second stage is a data exploration and the third stage is data verification. The results showed that tahfizh al-Qur'an at the Muhammadiyah Boarding School Klaten Islamic boarding school used the khifdhul jaded and khifdhul coding methods to memorize alQur'an. The khifdhul jaded method and the khfidhul coding method applied at the boarding school Muhammadiyah boarding school Klaten should be more focused so that it is more effective so that every year not only ten students who memorize the Koran will pass but more and more will pass the al-Qur'an memorizer. 'An. The khifdhul jaded method and the khfidhul coding method applied at the boarding school Muhammadiyah boarding school Klaten should be more focused so that it is more effective so that every year not only ten students who memorize the Koran will pass but more and more will pass the al-Qur'an memorizer. 'An. The concept of memorizing the Koran by using the khifdhul jaded method and the khifdhul coding method applied at the boarding school Muhammadiyah boarding school Klaten must be a rote method that will produce memorizers of the Koran with good memorization quality, according to the correct rules. Both in terms of the letter makharijul, recitation and from the way of reading it in a beautiful voice.
\end{abstract}

Keywords: method, learning, tahfizh al-Qur'an, MBS Klaten

\section{PENDAHULUAN}

Pondok Pesantren adalah sebuah lembaga pendidikan tertua di Indonesia. Setiap lembaga pendidikan, termasuk pesantren dituntut untuk memberikan pelayanan yang baik terhadap masyarakat. Salah satu tujuan berdirinya pondok pesantren, mahad, dan Lembaga pendidikan Islam adalah untuk mewujudkan filosofi pendidikan secara terintegrasi selain menghasilkan para huffaz akan tetapi juga memiliki keterampilan di semua bidang. Manajemen Islam prinsipnya unik karena sifatnya yang tidak hanya membimbing tetapi juga membentu perilaku individu secara spiritual dan moral. ${ }^{1}$ Agar dapat melakukan pelayanan terhadap masyarakat dengan baik, maka pesantren perlu dukungan sistem manajemen yang baik. Salah satu manajemen yang dimaksut di sini adalah manajemen dalam menerapkan suatu metode untuk menghafal Al-Qurean. Menghafal adalah salah satu metode yang

\footnotetext{
${ }^{1}$ G. Zaman, F. K. Afridi and M. Saleem. Islam and Management Principles: Evidence FromLiterature, Journal of
} Managerial Sciences, Vol. 7, No. 2, Jul-Dec 2013. 
digunakan oleh suatu lembaga pendidikan baik lembaga sekolah, pondok pesantren maupun lembaga-lembaga sekolah khusus penghafal Al-Qur'an.

Metode adalah cara yang digunakan untuk mengimplementasikan rencana yang telah disusun dalam suatu kegiatan nyata agar tujuan yang telah disusun tercapai secara optimal. ${ }^{2}$ Dengan adanya suatu metode akan bisa membantu seseorang menentukan keberhasilan menghafal Al-Qure an dan meningkatkan hafalannya secara terprogram. Di samping itu juga diharapkan dapat membantu hafalan menjadi efektif. Masalah mendasar yang dihadapi pengajaran pendidikan Islam di seluruh Indonesia adalah ketidak mampuan dan metode belajar mengajar yang tidak efektif. ${ }^{3}$ Pengajaran Islam di Lembaga lembaga pendidikan masih terbatas pada konseptualisasi dan hafalan. Dalam hal metode, sekolah harus mempunyai standar metode yang pas sesuai dengan kondisi siswa atau santri. Unsur strategi dalam gaya belajar tahfiz harus diberi perhatian khusus oleh semua pihak ketika menyusun kurikulum untuk pengajaran tahfiz dan belajar sehingga keunggulan dalam kualitas siswa dapat tercapai. ${ }^{4}$ Perencanaan pendidikan adalah keputusan yang diambil untuk melakukan tindakan selama waktu tertentu (sesuai jangka waktu perencanaan) agar penyelenggaraan sistem pendidikan menjadi lebih efektif dan efisien, serta menghasilkan lulusan yang lebih bermutu, dan relevan dengan kebutuhan pembangunan. ${ }^{5}$ Pentingnya komponen pengajaran dalam praktik mengajar guru. Untuk alasan ini, pelatihan dan kursus yang berkaitan dengan pengajaran Al-Qureeanharus ditingkatkan dan diperhitungkan oleh pihak yang bertanggung jawab. ${ }^{6}$ Sekolah memang harus menyiapkan terlebih dahulu kurikulum hafalan yang kira-kira menghasilkan kualitas dan kuantitas hafalan. Kualitas berhubungan dengan metode yang tepat untuk menghafal Al-Qur'an sedangkan kuantitas seberapa hasil yang didapatkan dengan kualitas metode tersebut.

Menghafal Al-Qurean bukanlah tugas dan suatu perkara yang mudah, salah satu upaya terpenting untuk diperhatikan dalam pembinaan hafalan Al-Qur ${ }^{\text {"e }}$ an adalah metode. ${ }^{7}$ Dalam melaksanakan metode menghafal Al-Qurean hendaknya dipandu dan dibimbing langsung oleh seorang pemandu hafalan yang berkompeten dalam penghafalan Al-Qurean, supaya hafalan yang sudah didapatkan bisa dipantau dan dibina oleh pemandu hafalan bila ada kesalahan dansebagainya. Menghafal al-Qur'an bukanlah hal yang mudah dilakukan oleh setiap muslim. ${ }^{8}$ Proses menghafal Al-Qur"ean mengharuskan seseorang untuk memiliki beberapa keterampilan sebelumnya yaitu untuk membaca Qur'an dengan baik, dengan tajwid yang tepat dan bacaan lancar. Baru kemudian seseorang mulai menghafal Al-Qur"an sehingga

\footnotetext{
${ }^{2}$ A. Majid. Strategi Pembelajaran, Cet. Ke 3, (Bandung: PT Remaja Rosdakarya, 2014), hlm. 193. Abas Asyafah. The Method Of Tadabur Qur"an: What Are The Student Views, Journal International Education Studies; Vol. 7, No. 6; 2014.

${ }^{3}$ Asyafah, Abas. 2014. The Method Of Tadabur Qur"an: What Are The Student Views, Journal International Education Studies, 7(6)

${ }^{4}$ Azmil Hashim. Correlation Between Strategy Of Tahfiz Learning Styles And Students Performance In AlQur" an Memorization (Hifz), Mediterranean Journal of Social Sciences, Vol. 6, No. 2S5, April 2015.

${ }^{5}$ Fattah, Nanang. Landasan Manajemen Pendidikan, (PT Remaja RosdaKarya, Bandung, 2013), hlm. 49.

${ }^{6}$ Mohd Aderi Che Noh, Amjad Hussein, Othman Ghani and Asmawati Suhid. The Study of Quranic Teaching and Learning: A Review in Malaysia and United Kingdom, Middle-East Journal of Scientific Research 15 (10): 1338-1344, 2013

7 Winarno Surakhmad. Pengantar Interaksi Mengajar-Belajar Dasar dan Teknik Metodelogi Pengajaran (Bandung: Tarsito, 1982), hlm. 96.

${ }^{8}$ Yahya, S.A.B. Al-Tibyan fi Adab Hamlah Al-Qur"ean, (Damsyik, Beirut. Maktabah Dar al-Quran, al-Muayyad, 1994), hlm. 16.
} 
akan menghasilkan hafalan yang baik dan kuat serta dapat mengingat semua 30 juz "dari AlQur'ean, individu muslim harus mengikuti aturan khusus untuk memastikan hafalannya benarbenar menempel baik dalam benaknya. Tidak ada keraguan bahwa di zaman modern seperti sekarang ini ada beberapa metode yang digunakan untuk reservasi dalam menghafalkan AlQur"ean. Lembaga pendidikan sudah pasti menerapkan metode menghafal Al-Qur an untuk siswa maupun para santrinya. Karena metode merupakan strategi untuk mencapai tujuan dari pembelajaran.

Penelitian ini dilakukan untuk mengungkap metode yang digunakan di pondok pesantren Muhammadiyah Boarding School Klaten. Muhammadiyah Boarding School Klaten merupakan sekolah yang berkurikulum KMI sistem modern, sederajat dengan MTs dan MA, yang langsung bernaung di bawah PDM Klaten. Pondok pesantren Muhammadiyah Boarding School Klaten mempunyai visi mewujudkan kader persyarikatan yang taat, berakhlak mulia, berilmu, mandiri, dan berprestasi. Dengan salah satu misinya adalah menerapkan tahfiz \& tafhim Al-Qurean. Adapun untuk program unggulan yaitu tahfidz Al-Qurean yang berupa hafal Al-Qurean minimal 5 Juz. Di sebagian Lembaga pendidikan terutama Lembaga pendidikan yang berlatar belakang pendidikan Islam hafalan Al-Qurean merupakan kurikulum yang menjadi unggulannnya, dengan menggunakan berbagai macam-macam metode sesuai kurikulum yang ditetapkan di Lembaga pendidikan tersebut. Demikina pula dengan Muhammadiyah Boarding School Klaten menerapkan metode dalam menghafal AlQur'ean. Metode apa yang diterapkan di pondok pesantren Muhammadiyah Boarding School Klaten untuk menghafal Al-Qurean. Tujuan penelitian ini untuk mengetahui sejauh mana metode yang diterapkan dalam menghafal Al-Qur"ean di Muhammadiyah Boarding School Klaten. Penelitian ini akan bermanfaat untuk mengetahui kualitas metode yang diterapkan di Muhammadiyah Boarding School Klaten dalam menghasilkan para penghafal Al-Qurean.

\section{METODE PENELITIAN}

Penelitian kualitatif ini merupakan pendekatan penelitian yang menghasilkan data deskriptif, merupakan data tertulis atau lisan dan perilaku orang yang dapat diamati. ${ }^{9}$ Pengumpulan data penelitian ini dilakukan dengan cara observasi, wawancara, dan dokumentasi. Observasi partisipatif moderat yaitu dilakukan untuk memperoleh data yang lengkap dengan cara peneliti mengikuti secara seksama proses pembelajaran tahflzh AlQur'ean dan terlibat langsung dalam proses pembelajaran tersebut. Jenis wawancara yang digunakan dalam penelitian ini adalah wawancara tidak terstruktur dengan menggunakan pedoman wawancara dan fleldnote. Wawancara dilakukan terhadap sie penanggung jawab tahfizh utama, sie penanggung jawab tahfizh kampus dan guru. Untuk melengkapi hasil observasi dan wawancara, dilakukan studi dokumen terkait proses pembelajaran tahflzh AlQur'ean dan lembaga yang melaksanakan. Setelah data terkumpul, selanjutnya akan dilakukan analisis data. Analisis data adalah suatu proses pengorganisasian data ke dalam pola, kategori, dan satu uraian dasar, sehingga dapat ditemukan dan dirumuskan hipotesis kerja. Ada beberapa tahapan yang akan dilakukan. Pertama akan dilakukan pereduksian data yang meliputi pemilihan, kategorisasi, dan pemilahan. Kedua, dilakukan eksplorasi data untuk memperjelas dan memperdalam data yang ditemukan. Ketiga dilakukan verifikasi data untuk

\footnotetext{
${ }^{9}$ Lexy, J. Moleong. Metode Penelitian Kualitatif, (Remaja Rosdakarya: Bandung, 2000), hlm. 167.
} 
membuktikan akurasi kebenaran data yang ada, dengan salah satu cara melakukan crosscheck dengan data lainnya.

\section{HASIL DAN PEMBAHASAN}

\section{Sejarah singkat pondok pesantren Muhammadiyah boarding school klaten}

Pondok Pesantren Muhammadiyah Sangkal Putung Klaten merupakan salah satu amal usaha Muhammadiyah yang diharapkan mampu menjadi media pencetak kader Muhammadiyah, kader umat dan kader bangsa. Dari amal usaha ini diharapkan dapat kita wujudkan ulama yang mampu membaca kitab, mandiri dan berjiwa wirausaha, serta dapat menegakkan dan mendakwahkan Islam berdasarkan Al-Qur'an dan Sunnah Shohihah sebagaimana faham Muhammadiyah. Pada tahun 2007 Sebelum menjadi boarding school pondok tersebut adalah madrasah tsanawiyah dan madrasah Aliyah muhammadiyah sangkal putung. Kemudian pada tahun 2014 dijadikan satu menjadi Pesantren Muhammadiyah Boarding School (MBS) dan semua santri harus berasrama. Dari tahun ke tahun santri MBS Klaten selalu meningkat dan memiliki tiga tempat yaitu kampus 1, kampus 2, dan kampus 3. Muhammadiyah Boarding School Klaten adalah salah satu lembaga pendidikan yang dikelola Pimpinan Daerah Muhammadiyah Klaten. Istimewanya, lembaga ini juga merupakan satusatunya lembaga bermodel boarding school (al madrasah ad dakhiliyyah) atau yang dikenal dengan nama Pondok Pesantren yang dimiliki PDM Klaten. Pondok ini diharapkan menjadi lembaga pencetak kader-kader Muhammadiyah yang loyal dan mumpuni di masa-masa yang akan datang. Oleh karena itu dalam visi pondok pesantren Muhammadiyah Boarding school disebutkan akan "Terwujudnya Kader Persyarikatan dan Ulama yang beriman, berilmu, berwawasan luas, berakhlak mulia, mampu membaca kitab, berbahasa Arab-Inggris aktif, mandiri dan berjiwa wirausaha dan kepemimpinan".

Model lembaga pendidikan yang dipandang sangat ideal untuk membentuk keimanan, karakter, dan mental hidup anak adalah lembaga pendidikan yang berasrama (boarding school). Karena dalam boarding school para anak didik hidup 24 jam dalam sistem yang dirancang secara sistematis untuk membentuk karakter, keimanan, dan mental hidup anak didik. Selain itu upaya pembentukan anak didik yang berkarakter, beriman, dan bermental hidup, mereka juga dididik menjadi kader persyarikatan. Sehingga mereka paham apa itu Muhammadiyah, tujuan dan bentuk gerakannya. Maka, Pondok pesantren sangat memperhatikan berbagai kegiatan yang menanamkan loyalitas persyarikatan santri, seperti HW, Kemuhammadiyahan, IPM, Baitul Arqam, Tapak Suci, dan berpartisifasi dalam kegiatan lain yang menumbuhkan kecintaan terhadap persyarikatan.

Di era sekarang, di mana arus globalisasi dan liberalisasi terasa semakin deras mempengaruhi konsep keimanan dan akhlakul karimah semua umat Islam, khusunya para generasi muda, meningkatnya kasus-kasus tentang kenakalan remaja, pergaulan bebas, konsumsi miras dan narkoba, semua itu merupakan hal-hal yang semakin meresahkan umat. Untuk itu dalam membentengi generasi kita dari hal-hal yang demikian, maka salah satu lembaga penting, selain rumah dan masyarakat, adalah lembaga Pendidikan. Konsep model kolegial di lembaga pendidikan terkait dengan konsep "jamaah". Dengan demikian, sangat penting bagi umat Islam untuk menyoroti dan menganjurkan prinsip-prinsip Islam model kolegial dalam arus utama wacana intelektual. model kolegial dari perspektif Islam akan meningkatkan budaya kolegialitas di lembaga pendidikan Muslim. Kepala sekolah Muslim 
harus memperhatikan tujuan model kolegial, struktur organisasi model kolegial, dan kepemimpinan transformasional dan partisipatif dalam model kolegial. ${ }^{10}$

DATA SANTRI MTS MBS KLATEN

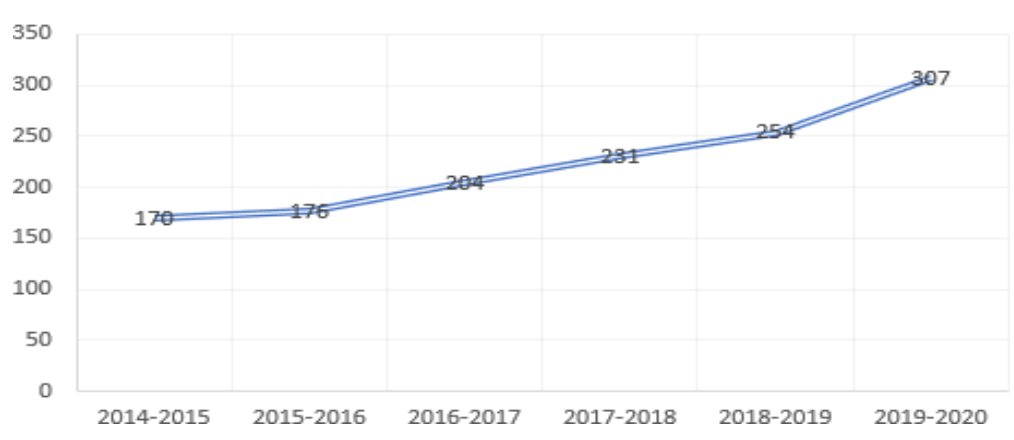

Gambar 1. Data Santri MTs MBS Klaten

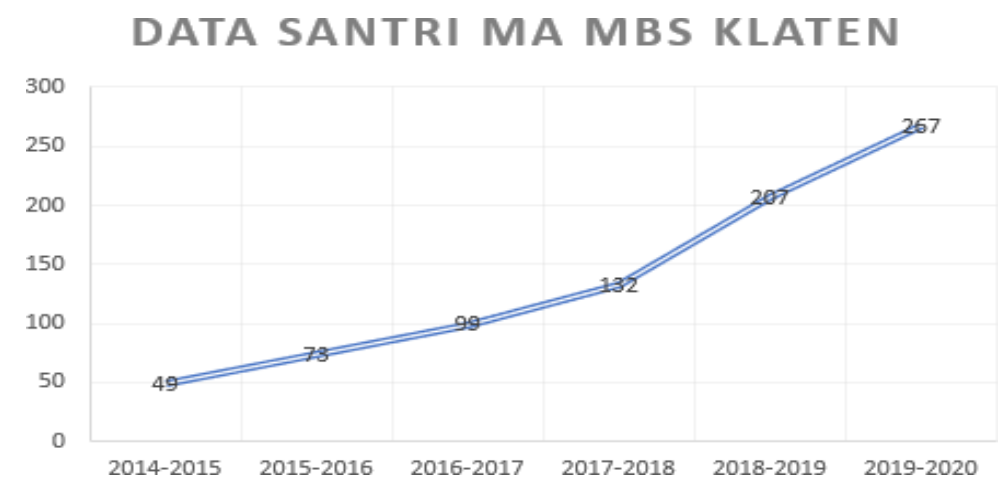

Gambar 2. Data santri MA MBS Klaten

Gambar 1 dan 2 menunjukan data santri di MBS Klaten yang setiap tahunnya selalu bertambah. Hal ini menunjukan bahwa MBS sudah banyak di kenal dan mendapatkan kepercayaan dari masyarakat baik di lingkungan daerah Klaten sendiri maupun masyarakat luar daerah Klaten, mengingat santri MBS bersal dari berbagai daerah di Indonesia. Di samping itu MBS Klaten juga sudah mempunyai fasilitas Gedung sendiri yang megah di beberapa yaitu kampus 1, Kampus 2, dan kampus 3, yang terletak tidak jauh dari pusat kota Klaten. Dengan melihat gambaran santri maupun fasilitas yang sudah memadai, tentunya manajemen pondok pesantren MBS tidak diragukan lagi termasuk manajemen hafalan Al-Qurean atau Tahfizdul Qurean yang menjadi program unggulan di pondok tersebut.

\section{Keadaan ustazd dan ustazdah}

Para pengajar di MBS Klaten terdiri dari 80 staf pengajar dari lulusan beberapa perguruan tinggi seperti alumni Universitas Al-Azhar Kairo-Mesir, Pondok Modern Gontor Jatim, perguruan tinggi baik negeri maupun swasta yang berkompeten di bidangnya. Sedangkan pengampu tahfizh di MBS Klaten terdiri dari 22 asatidzah dan ditambah mudir maechad. Berdasarkan uraian tersebut dapat dipahami bahwa bentuk pembinaan yang

\footnotetext{
${ }^{10}$ Azam Othman, Surayya Abu Bakar, Ahmad Faizuddin, Jama ${ }^{e e} a h$ And Collegial Model In Educational Institutions: Lessons And Principles Learned From Quran And Sunnah, Al-Shajarah, Journal Of Islamic Thought And Civilization Of The International Islamic University Malaysia (Iium), 2018.
} 
diterapkan di MBS Klaten tetap mengadopsi bentuk pembinaan yang diterapkan oleh Nabi Saw. Kepada sahabat di mana Nabi mengangkat beberapa orang sahabat untuk membantu mengajarkan Al-Qurean kepada sahabat yang lain. Ini berarti teori yang telah dikemukakan sebelumnya relevan dengan fakta yang ada.

\section{Keadaan Sarana dan Prasarana pondok pesantren Muahammadiyah boarding school Klaten}

Sarana-prasarana yang menjadi pusat kegiatan santri pondok pesantren MBS Klaten adalah Masjid. Masjid ini telah menjadi tempat kegiatan keagamaan khususnya sarana tempat pembelajaran tahfizh Al-Qurean sejak awal berdirinya pondok pesantren tersebut. Asrama selain sebagai tempat istirahat juga dijadikan tempat pembelajaran. Fasilitas lain yang disediakan adalah Mushaf Al-Qur'an, untuk mushaf Al-Qurean Muhammadiyah Boarding School merekomendasikan kepada seluruh santri untuk memakai Al-Qurean al-Huffadz. Alasan pondok pesantren MBS Klaten menggunakan mushaf tersebut karena mushaf tersebut memudahkan santri untuk menghafal. Akan tetapi pihak pondok pesantren MBS Klaten belum mewajibkan untuk memakai mushaf tersebut. Selai itu ada kitab-kitab tajwid baikyang lengkap dan berbahasa Arab maupun yang praktis dan berbahasa Indonesia yang digunakan salah satunya buku tuhfatul athfal dan pelajaran tajwid. Ini berarti bahwa sistem pembelajaran tahfizh Al-Qurean telah terlaksana dengan baik di pondok pesantren MBS Klaten.

\section{Metode Pelaksanaan Tahfizh Al-Qur'an di Pondokk Pesantren Muhammadiyah Boarding School Klaten}

Menghafal Al-Qurean dapat dikatakan sebagai penyimpanan dengan hati dan pengambilan teks al-Qur'an dengan mempraktikkan dan melafalkannya berulang-ulang, merupakan sebuah proses yang dikenal sebagai Hifz. Menghafal Al-Qur"an suatu kebutuhan umat Islam sepanjang zaman. ${ }^{11}$ Oleh karena itu, pada zaman Rasulullah Saw mereka para penghafal Al-Qurean mendapatkan kedudukan khusus sampai ketika mereka sudah menjadi syuhada ${ }^{e e}$.Umat Islam tidak akan meraih izzah-nya kecuali dengan kembali kepada Al-Qurean secara utuh. Awal dari semua ilmu yaitu menghafalkan kitabullah dan memahaminya, sedangkan Al-Qurean merupakan pokok dari semua ilmu, barang siapa yang menghafalkannya sebelum usiabaligh, kemudian meluangkan waktunya untuk mempelajari apa yang dapat membantu memahaminya yaitu bahasa Arab, maka hal itu adalah penolong untuk mencapai tujuan dalam menghafal dan memahami Al-Qurean dan Sunnah nabi Muhammad Saw.

Menghafal Al-Qurean merupakan proses dan usaha yang terus menerus dalam rangka untuk memelihara, menjaga dan melestarikan kemurnian Al-Qur'an yang diturunkan kepada Rasulullah Saw ke dalam pikiran dengan sengaja, serta sungguh-sungguh dengan tujuan selalu ingat dan menghindari adanya suatu perubahan dan pemalsuan serta dapat menjaga dari kelupaan baik secara keseluruhan maupun sebagiannya, sehingga mampu mengungkapkan kembali di luar kepala. Al-Qurthubi menyatakan apabila seseorang mendengarkan kitabullah dan sunnah Nabi-Nya, dengan penuh seksama disertai niatan yang benar seperti yang dikehendaki Allah, maka Allah akan memahamkannya serta akan

${ }^{11}$ Abdul Aziz Abdul Rauf. Kiat Sukses Menjadi Hafizh, (Bandung: Syamil, 2004), hlm. 1 
menjadikannya cahaya di dalam hatinya. Oleh karena itu seorang pengajar Al-Qurean akan menentukan kedudukan seseorang di akhirat kelak. Sehingga memilih seorang pengajar untukmenghafalkan Al-Qurean peranannya sangat besar.

Pondok pesantren Muhammadiyah Boarding School Klaten menjadikan tahfidzul Qurean sebagai program unggulan dikarenakan pertama;

1. Abdul Rauf menjelaskan di dalam sebuah hadits bahwa "sebaik-baik orang diantara kalian adalah orang yang mempelajari Al-Qur"ean dan mengajarkannya." (H.R. Bukhori) Hadits tersebut menunjukan bahwa ukuran kebaikan seseorang di sisi Allah ialah ketika ia diberi kesempatan oleh Allah untuk belajar dan memahami Al-Qur'ean kemudian mengamalkan dan mengajarkannya. ${ }^{12}$ Al-Qurean merupaka bukti kasih sayang dari Allah Swt kepada para hamba-Nya. Ia hadir sebagai pentunjuk dan membawa cahaya bagi kehidupan manusia menuju kebahagiaan abadi. Allah berfirman dalam Q.S. Asy-syura ${ }^{\text {ee }}$ 52, "Dan demikianlah kami wahyukan kepadamu (Muhammad) ruh (Al-Qur"ean) dengan perintah kami. Sebelumnya engkau tidaklah mengetahui apakah kitab (Al-Qurean) dan apakah iman itu, tetapi kami jadikan Al-Qurean itu cahaya, dengan itu kami memberi petunjuk siapa yang kami kehendaki di antara hamba-hamba kami. Dan sungguh engkau benar-benar membimbing (manusia) ke jalan yang lurus." "Dan sesungguhnya kedua hal itu yaitu Al-Qurean daniman merupakan sumber segala kebaikan di dunia dan di akherat. Memahmi keduanya merupaka suatu pengetahuan yang sangat agung dan paling utama. Bahkan pada hekekatnya tidak ada ilmu yang bermanfaat bagi pemiliknya selain ilmu tentang keduanya." Jadi menghafal al-Qur'an di mulai dari masa kanak-kanak dan masa muda merupakan bagian mencontoh salaf sholeh, menapaki setiap jejak mujahadah (kesungguhan) mereka dan menempuh contoh jalan hidayah Allah. ${ }^{13}$

Dengan adanya program tahfidhul Qurean di Muhammadiyah Boarding School Klaten diharapkan akan mampu memperbaiki dan merubah akhlak santri dari yang belum baik menjadi lebih baik. Dengan membaca Al-Qurean diharapkan seseorang bisa mendapat ilmu baru untuk memperbaiki hidupnya. Diapun juga bisa mendapat pencerahan yang lebih baik untuk hidupnya seperti hidayah, dan Al-Qur'an akan memberi jalan bagi seseorang untuk menjadi lebih baik. Orang yang menghafal al- Qur'an bisa dilihat dari moral dan sikap mereka.

2. Menghafal Al-Qurean merupakan salah satu cara untuk meningkatkan kecerdasan seseorang. Dengan banyak menghafal otak akan lebih cepat menyerap informasi dan juga menyimpannya dalam jangka waktu lama. Semakin seseorang sering membaca Al-Qurean ternyata melatih dan juga meningkatkan otak dalam mencerna informasi. Menurut Louis Thurstone salah satu ciri orang yang cerdas adalah memiliki daya ingatan yang kuat. ${ }^{1414}$ Daya ingatan seseorang bisa dipengaruhi oleh proses hafalan dan Latihan. Ada perbedaan yang signifikan dalam pencapaian akademik sebelum Huffaz dan sesudah Hifz. ${ }^{1515}$ Selain

\footnotetext{
${ }^{12}$ Abdul Aziz Abdul Rauf. Pedoman Daurah Al-Qureean : Panduan Ilmu Tajwid Aplikatif. (Jakarta : Markaz AlQurean, 2015), hlm. 12

${ }^{13}$ Ibnu al-Qoyyim al-Jauziyyah. ,al „ilmu fadluhu wa syarfuhu, majmu“ah at-tuhfa an-Nafais ad-Dauliyyah, 1996.

${ }^{14}$ Djaali. Psikologi Pendidikan, (Jakarta: Bumi Aksara, 2008), hlm, 15

${ }^{15}$ Nazia Nawaz1 \& Syeda Farhana Jahangir. Effects of Memorizing Quran by Heart (Hifz) On Later Academic Achievement, Journal of Islamic Studies and Culture, June 2015, Vol. 3, No. 1, pp. 58-64, DOI: 10.15640/jisc.v3n1a8.
} 
itu analisis konten menunjukkan keseluruhan berdampak positif pada pendidikan dan kehidupan sosial-budaya Huffaz. Menghafal itu diindikasikan terkait dengan prestasi akademik peserta. Selanjutnya, hal itu dianggap sebagai alat yang efektif untuk pemberdayaan otak, peningkatan ilustrasi, dan orasifitur. ${ }^{1616}$ Mengajar menghafal AlQurean adalah melalui pengucapan yang benar, penggunaan mushaf tertentu, mengatur tingkat menghafal, pembacaan doa sebelum menghafal dan lain-lain, para peneliti mengklaim bahwa menghafal Qurean telah memberi dampak besar kepada huffaz Qur"ean serta memiliki catatan akademik yang luar biasa. ${ }^{1717}$ Usia muda, yaitu usia pra sekolah hingga SMA menghafal Al-Qurean sangat urgen dan ditekankan untuk ditanamkan dalam ingatan mereka agar ingatan mereka yang masih bersih terisi dengan hal-hal yang bermanfaat. Maka dari itu, orang tua dan para pendidik hendaknya memberikan perhatian dan bimbingan yang tepat agar generasi muda ini menjadi generasi yang bermanfaat bagi agama.

Berdasarkan analisis yang dilakukan tentang pembelajaran metode tahfizh Al-Qurean di MBS Klaten Pondok pesantren Muhammadiyah boarding school klaten menggunakan dua dasar metode dalam menghafal Al-Qur'an. Metode ini di namai metode khifdhul jadid dan khifdhul qodim. Para santri diharuskan menghafal berdasarkan kemampuan mereka. Mulai dari setengah halaman, hingga mencapai sekitar empat halaman Al-Qurean Rasm Uthmani. Dengan mempraktikkan metode ini, santri dapat membaca semua 30 juz dengan menghafal, tanpa melihat mushaf Al-Qur'ean.

a. Metode Khifdhul jadid

Khisdhul Jadid adalah istilah yang digunakan untuk menggambarkan hafalan barupara santri. Menurut yahya, khifdhul jadid adalah hafalan baru santri yang di setorkan pada pembimbing halaqoh. Hafalan baru tersebut tergantung kepada kemampuan dan kesungguhan seorang santri. Biasanya satu kali setoran antara setengah lembar sampai 2 lembar. Khifdhul jadid merupakan perkara asas bagi semua penghafal Al-Qurean. Jika tidak ada hafazan baru, bagaimana bisa menyelesaikan hafalan 30 juz. Perbedaannya hanya dalam hal cepat atau lambat, banyak atau sedikit serta rajin atau malas bagi para penghafal.

b. Metode khifdhul qodim

Dijelskan yahya khifdhul Qodim adalah mengulang hafalan lama yang disetorkan kepada pembimbing halaqoh. Khifdhul qodim ini sama dengan muroja ${ }^{\text {ee }}$ ah, contohnya jika seorang santri sedang menghafal juz 3 maka juz 1 sampai juz 2 adalah khifdhul qodim. Alasan pondok pesantren menggunakan metode khifdhul jadid dan khifdhul qodim dikarenakan pertama; karena mudah dan memudahkan santri untuk menghafal.

Tabel 1. Jam Wajib Menyetorkan Hafalan bagi Santri

\begin{tabular}{|c|c|c|c|c|c|c|}
\hline No & Jam wajib & Mulai pukul & $\begin{array}{c}\text { Berakhir } \\
\text { pukul }\end{array}$ & Jenis kegiatan & Keterangan & Tempat \\
\hline 1 & Pagi & 05.00 & 06.00 & Khifdhul Jadid & Setiap Pagi & Masjid \\
\hline 2 & Malam & 19.00 & 20.30 & Khifdhul Qodim & Setiap Malam & Masjid \\
\hline
\end{tabular}

\footnotetext{
${ }^{16}$ Muhammed Yusuf. Memorization As A Learning Style: A Balance Approach To Academic Excellence, Oida International Journal Of Sustainable Development, Vol. 01:06. . Pp. 49-58. 2010.

${ }^{17}$ Muhaidi Mustaffa. Muhammad Fathi Yusof, Mohd Ai ${ }^{i e} i k h s a n$ Ghazali And Siti Salwa Md. Sawari, Descriptive Qualitative Teaching Method Of Memorization In The Institution Of Tahfiz Al-Quran Wal Qiraat Pulai Condong And The Students ${ }^{\text {ee }}$ Level Of Academic Excellence, Mediterranean Journal of Social Sciences, Vol 7 No 1 S1, Januari 2016, Doi:10.5901/mjss.2016.v7n1s1p79.
} 
Tabel di atas menunjukan bahwa kegiatan Khifdhul jadid para santri pondok pesantren Muhammadiah Boarding School Klaten sudah terjadwal sesuai yang ditetapkan oleh pondok. Yaitu mulai selesai sholat subuh dari pukul 05.00 sampai pukul 05. 30, kemudia dilanjutkan untuk khifdhul qodim selesai sholat isya dari pukul 19.00 sampai pukul 20.30. Karena khifdhul jadid maupun khifdhul qodim merupakan kewajiban santri untuk 9 enyetorkan hafalan, oleh karena itu mereka akan duduk di depan pembimbing halaqoh beserta kelompoknya yang terdiri dari 10 orang perkelompok. Para pembimbing halaqoh akan mencatat kemajuan prestasi mereka dalam buku-buku khusus yang sudah disiapkan untuk para santri. Disamping jadwal yang sudah di tetapkan oleh pondok, khifdhul jadid dan khifdhul qodim bisa sewaktu-waktu diterapkan tergantung sesuai kebutuhan para santri dan kesediaan para pembimbing halaqah. Menurut Luffiyah, secara keseluruhan, para santri memiliki banyak waktu untuk menambah hafalan baru disetiap harinya, yang kemudian di setiap pagi para santri baru menyetorkan hafalan baru tersebut pada pembimbing halaqoh. Dalam menghafal Al-Qurean harus ditanamkan keyakinan di hati bahwa tidak ada waktu yang tidak bisa digunakan untuk menghafal. Setiap saat diwaktu malam maupun siang adalahwaktu yang baik untuk menghafal Al-Qurean. Ada waktu-waktu yang mudah untuk kegiatan hafalan, atau lebih baik, bila dilihat dari sisi kejernihan pikiran dan kemampuan otak untuk merenungkan ayat-ayat Al-Qur'ean. ${ }^{18}$ Waktu tersebut contohnya saat sahur, di pagi hari buta, dan sebelum tidur. Berdasarkan keterangan di atas dapat dipahami bahwa dalam menerapkan sistem pembelajaran metode tahfizh Al-Qur"ean maka pengaturan waktu yang baik harusditerapkan, selain untuk efisiensi dan efektifitas pembelajaran juga untuk melatih kedisiplinan para santri dalam menggunakan waktu.

Table 2. Konsep Tahfzidul Qur'an di MBS Klaten

\begin{tabular}{|c|c|c|c|}
\hline $\begin{array}{c}\text { Bagi Yang Telah Selesai } 30 \\
\text { Juz }\end{array}$ & Bagi Ustadz Ustadzah & Bagi Santri Khusus & $\begin{array}{l}\text { Bagi Santri Non } \\
\text { Khusus }\end{array}$ \\
\hline $\begin{array}{l}\text { - Muroja }{ }^{\text {ee } a h ~ d e n g a n ~} \\
\text { membaca } 3 \text { juz perhari } \\
\text { - Penyetoran } 2 \text { lembar } \\
\text { perhari } \\
\text { - Juziyahsetiap10hari, 2x } \\
\text { atau1x duduk. }\end{array}$ & $\begin{array}{l}\text { Satu bulan } 1 \text { juz. } 1 \text { juz } \\
\text { dibagi untuk } 5 \text { orang } \\
\text { (muraja }{ }^{\text {ee }} \text { ah } 1 \text { halaman } \\
\text { setiap hari, selama } 5 \text { hari } \\
\text { 1/4 juz). Setiap pekan } \\
\text { menyelesaikan } 1 / 4 \text { juz } \\
\text { sampaiselesai1juz. } \\
\text { - Oneday one juz } \\
2 \text { lembar dibaca ketika } \\
\text { sebelum atau selesai } \\
\text { sholat. }\end{array}$ & $\begin{array}{l}\text { - Juziyah bisadibagi } \\
\text { menjadi 4x2x1x } \\
\text { - Oneday one juz } \\
2 \text { lembar dibaca ketika } \\
\text { sebelum atau selesai } \\
\text { dholat } \\
\text { - Muroja"ah wajib hafalan } \\
\text { target kelas } \\
\text { - Minimal setoran } 1 \\
\text { lembar }\end{array}$ & $\begin{array}{l}\text { - One day one juz } \\
2 \text { lembar dibaca ketika } \\
\text { sebelum sholat atau } \\
\text { setelah sholat } \\
\text { - } \\
\text { Focus muroja }{ }^{\text {ee } a h} \\
\text { hafalan untuk } \\
\text { murojae ah target kelas } \\
\text { - Juziyah } 5 \times 4 \times 2 \times 1 x\end{array}$ \\
\hline
\end{tabular}

Kalau melihat daftar konsep pada tabel di atas bahwa hafalan Al-Qur"ean pondok pesantren Muhammadiyah Boarding School Klaten di atas, ternyata terdiri dari bagianbagiankelompok baik dari para ustad/ustadzah, santri dan para santri yang sudah menghafal 30 sebagai santri pengabdian. Santri yang sudah menyelesaikan 30 juz tetap akan menyetorkan hafalannya karena masih mengabdi di Muhammadiyah Boarding School Klaten. Mereka para santri yang sudah menghafal sampai 30 juz terdiri dari santri dan santriwati yang jumlahnya 10 orang. Pada akhir wisuda mereka mendapatkan sertifikat yang menyatakan

\footnotetext{
${ }^{18}$ Muhammad Habibillah Muhammad Asy-Syintiqi. Kiat Mudah Menghafal Al-Qurean, (Solo: Gazzamedia, 2011), hlm. 78
} 
bahwa mereka sudah menyelesaikan hafalan sampai 30 juz. Dastar bandi adalah teknik sertifikat kelulusan yang diberikan kepada siswa yang menyelesaikan pembacaan mereka dan dapat lulus ujian dalam metode Panipati. ${ }^{19}$ Setelah berhasil lulus dalam tertib wifak, siswa akan menerima Sertifikat Penghafalan Al-Qur"ean khusus dari Jami'ah Darul Qur"an Pakistan. Acara khususini dikenal sebagai Dastar Bandi atau Konvokasi. Menurut Abdurrohman bahwa setiap santri yang akan ujian kelulusan menghafal Al-Qurean akan diuji untuk memperkuat hafalan sebelum ujian akhir kelulusan menghafal. Setiap santri apabila sudah menyelesaikan hafalan1 juz maka wajib mengulangi kembali, dengan cara dari halaman dengan halaman yang lain diikat menjadi satu. Kemudia jika 5x artinya boleh 1 juz dibagi menjadi 2 lembar sekali duduk, dan maju ke pembimbing 5x. Kemudian boleh juga 4x artinya 2,5 lembar $x 4$ pertemuan sama dengan 1 juz. Boleh $2 \mathrm{x}$ artinya 5 lembar $\mathrm{x} 2$ pertemuan sama dengan 1 juz. Sedangkan $1 \mathrm{x}$ artinya sekali duduk menyetorkan hafalan langsung 1 juz.

Dari konsep tersebut terbagi antara santri khusus dan santri non khusus. Bagi santri khusus artinya konsep itu diikuti para santri yang mempunyai kemauan tinggi untuk cepat mendapatkan hafalan yang banyak. Maka mereka akan semakin terasah dengan konsep menghafal seperti ini dan mereka menjadi terbiasa dengan konsep tersebut, untuk anak-anak yang mampu hanya tinggal memberikan motivasi dan metode untuk menghilangkan kejenuhan mereka serta mencari cara agar mereka menghafal dan muroja ${ }^{e e}$ ah atas kemauan sendiri. Sedangkan bagi santri yang non khusus artinya konsep ini diikuti bagi santri yang tidak mempunya target cepet selesai akan tetapi mereka juga mengikuti peraturan yangditetapkan pihak pondok pesantren. Menurut yahya kalau melihat konsep yang disesuaikan dengan metode hafalan target hafalan ini akan mudah didapat dari santri non khusus sebanyak $98 \%$ dibanding dengan santri khusus yang hanya mendapatkan $70 \%$ karena santri khusus lebih berat, Jadi misal di includekan kedua konsep tersebut sudah mencapai target. Sehingga dengan diterapkannya metode khifdhul jadid dan khifdhul qodim dari 600 santri baik dari santri khusus maupun santri non khusus menyatakan bahwa metode tersebut sangat efektif. Dan masih menurut yahya bahwa tahun ajaran 2019/2020 MBS Klaten sudah meluluskan 10 santri penghafal Al-Qur"ean terdiri dari santri Mts dan MA.

Efektivitas adalah adanya kesesuaian antara orang yang melaksanakan tugas dengan sasaran orang yang dituju dan bagaimana suatu organisasi berhasil mendapatkan dan memanfaatkan sumber daya dalam usaha mewujudkan tujuan operasional Pembelajaran efektif mengarah pada terukurnya suatu tujuan dari belajar. Pembelajaran dianggap efektif apabila sekor yang dicapai oleh siswa memenuhi batas minimal kompetensi yang telahdirumuskan. ${ }^{2020}$ Proses belajar-mengajar dapat dikatakan berhasil baik, apabila kegiatan belajar-mengajar tersebut dapat membangkitkan proses belajar. Karena penentuan atau ukuran dari pembelajaran yang efektif terletak pada hasilnya. Efektifitas dapat dijadikan sebagai patokan untuk mengukur keberhasilan suatu pendidikan yang mencerminkan sejauh mana tingkat keberhasilan tersebut telah dicapai oleh peserta didik atau para santri dalam mencapai suatu tujuan pendidikan yang telah ditentukan. Efektivitas yang dimaksud dalam penelitian ini adalah hasil yang dicapai dalam menghafal Al-Qurean santri di pondok pesantren Muhammadiyah Boarding School Klaten dengan metode menerapkan khifdhuljadid dan khifdhul qodim.

\footnotetext{
${ }^{19}$ Sedek Ariffin. Implementation Of Panipati Method On Memorization The Quran In Malaysia: A Study In Tahfiz Institute, ITMAR-2014Full Paper Proceeding/Vol-1,406-413. 2014

${ }^{20}$ E. Mulyasa. Kurikulum yang di sempurnakan, (Bandung: PT Remaja Rosdakarya. 2006), hlm. 89.
} 


\section{Metode Tadabbur Qur'an dalam Pengajaran Pendidikan Islam}

Metode adalah prosedur yang sistematis dan praktis dirancang untuk mencapai tujuan tertentu. Tadabbur dimaksutkan mengungkap dari yang tersembunyi melalui kontemplasi. ${ }^{21}$ Jadi, tadabbur Qur'an merujuk pada cara instruksi praktis yang memerlukan kombinasi pendekatan dan dilakukan dengan cara yang reflektif. Al-Qur'an merupakan sumber utama ajaran Islam. Allah memerintahkan manusia yang berkaitan dengan hal belajar mengajar terdapat dalam surat ale Alaq dari 1-5, Surat tersebut memerintahkan manusia untuk membaca, mempelajari, belajar atau melakukan suatu penelitian ilmiah, bahkan untuk saling mengajar.

Muhammad menjelaskan dalam tafsir Ibnu Katsir disebutkan bahwa mula-mula wahyu al-Qur'an yang diturunkan adalah ayat-ayat ini yang mulia lagi diberkati, ayat-ayat ini merupakan suatu permulaan rahmat yang diturunkan oleh Allah karena rasa kasih saying Allah kepada hamba-hamba-Nya, merupakan nikmat yang mula-mula diberikan oleh Allah kepada mereka. ${ }^{22}$ Surat ini di dalamnya terkandung peringatan yang menggugah manusia kepada asal mula penciptaan manusia, yaitu dari 'alaqah. Di antara kemurahan Allah Swt ialah Dia telah mengajarkan kepada manusia apa yang tidak diketahuinya. Melihat hal ini berarti Allah telah memuliakan dan menghormati manusia dengan ilmu-Nya. Dan ilmu tersebut merupakan bobot tersendiri yang membedakan antara Abul Basyar (Adam) dengan malaikat. Terkadang ilmu berada di akal pikiran, dan terkadang juga berada dalam lisan, juga terkadang pula berada dalam tulisan. Secara akal. Lisan dan tulisan mengharuskan perolehan ilmu dan tidak sebaliknya. Karena itulah disebutkan dalam Al-Qurean firman-Nya: Bacalah, dan Tuhanmulah Yang Maha Pemurah, Yang mengajar (manusia) dengan perantaraan qalam. Dia mengajarkan kepada manusia apa yang tidak diketahuinya. (Al-'Alaq: 3-5). Di dalamatsar disebutkan "Ikatlah ilmu dengan tulisan." Dan masih disebutkan pula dalam asar, bahwabarang siapa mengamalkan apa yang diketahuinya, maka Allah akan mewariskan kepadanya apa yang tidak diketahui sebelumnya. Belajar merupaka suatu dasar untuk pengembangan pengetahuan, dan juga merupakan landasan iman dan kepercayaan. Maka dari itu belajar adalah aktivitas penting dalam kehidupan manusia karena manusia adalah khalifah di muka bumi.

Al-Qur'ean adalah petunjuk bagi umat manusia, cahaya kehidupan serta prinsip-prinsip dalam menjalani hidup di dunia. Segala yang dibutuhkan manusia sudah diterangkan dalam Al-Qurean, baik secara eksplisit, implisit, atau isyarat. Para sahabat nabi dan para pengikut memperhatikan Al-Qur'an dengan perhatian maksimal dari berbagai sisi, seperti aspek tilawah (baca), tahfidz (hafalan), pemahaman, tadabbur, dan pengamalan. Namun umat zaman ini, karena kelemahan mayoritasnya, dalam interaksi mereka dengan Al-Qur' an hanya menitik beratkan pada aspek baca, dan hafalan saja, meninggalkan aspek utama, yaitu memahamami dan mentadabburi. Kebiasaan seperti ini menjadikan aspek pengamalan AlQur"ean menjadi sesuatu yang mewah. Sungguh Allah telah menurunkan Al-Qur an, dan memerintahkan kita untuk mentadabburinya, dan Allah sudah menjamin akan menjaganya (menghafalnya), namun kita malah sibuk menjaganya (menghafalnya), meninggalkan mentadabburinya. ${ }^{23}$

\footnotetext{
${ }^{21}$ Abas Asyafah. The Method of Tadabur Qureean: What Are the Student Views?, International Education Studies; Vol. 7, No. 6; 2014.

${ }^{22}$ Abdullah bin Muhammad. Tafsir Ibnu Katsir, Jilid 8, (Bogor: Pustaka Imam Sfafie I, 2004), hlm. 505

${ }^{23}$ Abdul Karim Bakar. Haula at-Tarbiyah wa at-Ta"lim. (Damaskus: Dar al-Qalam, 2011), hlm. 226
} 
Menurut yahya bahwa selain menghafalkan Al-Qurean para santri Muhammadiyah Boarding School Klaten yang sudah menghafal 30 juz ada kewajiban untuk meroja a ah serta mentadabburi Al-Qur'an, dan salah satu caranya adalah dengan kewajiban mereka yang sudah lulus Madrasah Aliyah pengabdian di pondok selama satu tahun dengan tujuan ilmu yang sudah di dapat disampaikan ke santri lain. Tujuan dasar diturunkan Al-Qurean adalah supaya manusia mendatabburinya dan mengambil pelajaran darinya, bukan sekedar hanya untuk dibaca saja meskipun pahalanya banyak. Mentadabburi Al-Qurean tidak hanya sekedar mambaca Al-Qurean dengan menjaga huruf-hurufnya, makhraj-makhrajnya akan tetapi memahami isi yang terkandung di dalamnya dan mengamalkan serta mengajarkannya.

Adab-adab membaca Al-Quree an adalah mentadabburi kandungan-kandunganya. ${ }^{24} \mathrm{Al}$ Qur'an memberi petunjuk, dan makna-makna yang tidak terbatas, dengan kalimat yang terbatas. ${ }^{25}$ Allah menjelaskan bahwa Al-Qurean tidak diturunkan melainkan supaya manusia mentadabburi ayat-ayatnya dan memahami kandungan isinya, firman Allah dalam Al-Qurean surat ke 38: 29 menyatakan bahwa, "Kitab Al-Qur"ean kami turunkan kepadamu penuh berkah agar mereka menghayati ayat-ayatnya dan agar orang-orang yang berakal sehat mendapat pelajaran. Dalam tafsir al-Sa ${ }^{e e}$ di menjelaskan, mengenai berkah Al-Qurean, bahwa dalam alQur`an terdapat kebaikan dan ilmu yang sangat banyak. Di dalamnya terdapat petunjuk agar terhindar dari segala kesesatan, obat dari segala penyakit, cahaya untuk menerangi kegelapan-kegelapan, setiap hukum yang diperlukan manusia dan dalil yang tegas tentang segala yang diinginkan sehingga menjadikannya semulia-mulia kitab yang diturunkan Allah Swt.

Untuk mendapatkan berkah dari Al-Qurean salah satunya berupa ilmu, obat, cahaya dan segala bentuk kemanfaatan dibutuhkan pemahaman, perenungan, serta tadabbur ayatayatnya secara terus menerus, berulang-ulang secara periodik. Karena Tadabbur merupakan cara berinteraksi terhadap Al-Qur"ean. Dia adalah sebaik-baik amal karena dengan tadabbur berkah Al-Qur"ean, ilmu, obat, dan cahaya Al-Qur'ean bisa diusahakan, berbeda dengan hanya membaca cepat tanpa pemahaman. Tadabbur Al-Qurean berfungsi menyadarkan orang dari pingsan, membuka jendela-jendela, mengusahakan cahaya, menggerakkan rasa, menjadikan hati bergelora, mensucikan nurani, menghidupkan jiwa, menyinari dan mencahayainya. ${ }^{26}$ Tadabbur adalah benteng utama Islam untuk menjaga kemuliaannya dan membangun kembali peradabannya. ${ }^{27}$ Ketika kaum muslimin bersikap adil kepada diri mereka sendiri, tentunya mereka tidak akan meninggalkan Al-Qur"ean, apabila mereka mentadabburi kandungan Al-Qurean, dan mereka mengetahui apa yang telah Allah tetapkan sebagai jalan kehidupan yang terbaik, tentu mereka tidak akan berada dalam ketertinggalan seperti sekarang, karena Al-Qurean sebenarnya mengarahkan kepada petunjuk, sekaligus sebagai cahaya bagi umat, jalan yang lurus, kunci kebahagiaan, kunci untuk mencapai sebuah kemaslahatan, terbagunnya kembali umat dan peradabannya. ${ }^{28}$

\footnotetext{
${ }^{24}$ Yusuf al-Qardawi. Kaifa Nataee amal maea al-Qurean, (Kairo: Dar al-Shuruq, 1999), hlm. 169

${ }^{25}$ Abd al-Rahman al-Sa ${ }^{e e}$ di, Abd al-Rahman al-Sa ${ }^{e e}$ di, Taisir al-Karim al-Rahman fi Tafsir Kalam al-Mannan, (T.p, Muassasah al-Risalah, 2000), hlm. 712.

${ }^{26}$ Sayyid Qutb. Fi Dilal Al-Qurean, (Beirut: Dar al-Shuruq, 1992), hlm. 23

${ }^{27}$ Muhammad al-Ghazali. Kaifa Nata ${ }^{e e}$ amal Maeea Al-Qurean, (Mansurah: Dar al-Wafaee, 1992), hlm. 180.

${ }^{28}$ Wahbah Zuhaili. Al-Tafsir Al-Munir, Vol V, (Damaskus: Dar al-Fikr, 2003), hlm. 172
} 


\section{Implikasi Mengahafal Al-Qur'an bagi Generasi Muslim}

Islam telah mengajarkan bahwa segala urusan dan problematika di masyarakat adalah tanggung jawab serta amanah yang dibebankan kepada pemuda. Dan di dalam ajaran Islam menuntut semakin tinggi jenjang pendidikan seseorang, maka semakin tinggi akhlak dan moral yang tertanam di hatinya. Seorang muslim haruslah senantiasa berpegang teguh pada nilai-nilai dalam ajaran Islam. Di Setiap aktivitas dan perannya seyogyanya berdasarkan kepada sumber ajaran Islam. Akhlak dan moral yang melekat pada seorang muslim bersumber kepada AlQur'an dan Sunnah Nabi Saw. Karena kedua sumber inilah yang menjadi barometer kualitas akhlak dan moral seorang muslim. Siapapun yang dekat dan menjadikan pedoman dengan kedua sumber ajaran Islam ini, maka pastilah mempunyai kualitas akhlak yang baik. Menyatakan bahwa, menempatkan akhlak pada sains adalah tanggung jawab bersama karena hal itu mencakup implikasi doktrinal bahwa tujuan hidup manusia harus berada dalam kerangka pemujaan kepada Allah. ${ }^{29}$

Mekanisme untuk melawan potensi invasi budaya sangat penting bagi seluruh umat Islam pada umumnya dan para pendidik Muslim pada khususnya. Pendidikan merupaka alat yang paling penting di antara semua cara untuk melawan nilai-nilai asing yang terkandung dalam bahasa asing, terutama yang terkenal secara global. Nilai-nilai Barat yang tertanam dalam buku teks bahasa Inggris dimanifestasikan secara eksplisit dan implisit. ${ }^{30}$ Studi ini jugamenunjukkan bahwa ada kontradiksi yang cukup besar antara nilai-nilai ini dan nilainilai yang disebarkan dalam buku teks lain yang digunakan oleh siswa yang sama untuk mata pelajaran lain, serta dengan nilai-nilai yang disebarkan oleh guru dan orang tua. Maka denganPendidikan budaya Islam sejak dini yaitu membiasakan dengan Qur ${ }^{\text {rean akan }}$ tumbuh perilaku seseorang akan senantiasa diiringi nilai-nilai spiritual akhlak Al-Qurean akan melekat pada diri orangmuslim.

Al-Qurean merupakan kumpulan petuah dan sebuah pelajaran. Rasulullah sendiri telah memberikan penghargaan kepada umat manusia bahwa yang paling mulia di antara umat Rosulullah ialah orang yang memiliki Al-Qurean di dalam jiwanya. Salah satu cara membentuk akhlak pada generasi muslim adalah dengan mendekatkan diri pada Al-Qur'an yaitu menghafalkannya. Bahwa hati, fikiran, dan perilaku seseorang akan senantiasa diiringi nilai- nilai spiritual dengan menghafal Al-Qurean, sehingga akhlak Al-Qur an akan melekat pada diri orang muslim. Apabila Hati dipenuhi oleh kemaksiatan dan senantiasa disibukkan dengan kerakusan nafsu syahwat maka tidak akan ada tempat untuk cahaya Al-Qurean. Kemaksiatan tersebut akan menghalangi hafalan Al-Qurean, sedangkan bisikan syetan akan selalu menjauhkan diri dari mengingat Allah. Sudah waktunya Lembaga-lembaga pendidikan memikirkan sebuah konsep kurikulum yang mengajarkan akan pentingnya menghafal AlQur'ean, tidak hanya di terapkan di Lembaga pendidikan yang berlatar belakang agama saja akan tetapi perlu juga diterapkan pada Lembaga-lembaga pendidikan negeri milikpemerintah. Karena apabila suatu konsep pembelajaran Al-Qureean di terapkan di sekolah baik sekolah berlatar belakang agama dan sekolah berlatar belakang umum atau negeri, dan sesuai ajaran

\footnotetext{
${ }^{29}$ Meti Fatimah. Concept of Islamic Education Curriculum: A Study on Moral Education in Muhammadiyah Boarding School, Klaten, Jurnal Didaktika Religia, Vol. 6, No. 2, 2018, DOI: 10.30762/didaktika. v6i2.1103.

${ }^{30}$ Merah Souad, Tahraoui Ramdane, Nor Hayati Husin, Madihah Khalid, Noor Lide Abu Kassim and Suzana Suhailawaty Md Sidek. 2018. Muslim studentse perception of western values as presented in english text books: international islamic school Malaysia (secondary) as a case study, al-Shajarah journal of Islamic thought and civilization of the International Islamic university Malaysia (iium), 2018.
} 
Islam maka akan lahir generasi Islam yang memiliki akhlak yang luhur dan berprestasi di dalam masyarakat karena setiap aktivitasnya merupaka cerminan dari Al-Qur"an. Meskipundi sekolah umum sudah menyediakan waktu pelajaran agama dengan tambahan untuk baca, tulis, Al-Qurean (BTA) akan tetapi belumlah menghasilkan target yang diharapkan, di karenakan adanya keterbatasan waktu, kurangnya sumber daya manusia (SDM) serta biaya.

\section{KESIMPULAN}

Pondok pesantren merupakan Lembaga pendidikan Islam untuk mempelajari, dan mengamalkan ajaran Islam dengan sangat menekankan akan pentingnya moral keagamaan sebagai pedoman terhadap perilaku sehari-hari. Seiring dengan berjalannya waktu kini banyak bermunculan sekolah-sekolah yang menerapkan metode boarding school, dengan menawarkan program hafalan Al-Qur'ean sebagai program unggulan sekolah tersebut. pondok pesantren Muhammadiyah boarding school klaten, dalam meningkatkan kualitas dan kuantitas hafalan Al-Qur'ean menggunakan metode khifdhul jadid dan khifdhul qodim. metode khifdhul jadid dan metode khfidhul qodim yang diterapkan di pondok pesantren Muhammadiyah boarding school klaten harus lebih di fokuskan lagi supaya lebih efektif sehingga setiap tahunnya tidak hanya meluluskan sepuluh santri penghafal Al-Qurean sajaakan tetapi lebih banyak lagi meluluskan para penghafal Al-Qur"an. Konsep menghafal Al-Qurean dengan menggunakan metode khifdhul jadid dan metode khifdhul qodim yang diterapkan di pondok pesantren Muhammadiyah Boarding School Klaten harus menjadi metode hafalan yang akan menelurkan para penghafal Al-Qur"an dengan kualitas hafalan yang baik, sesuai dengan kaidah yang benar baik itu dari segi makharijul hurufnya, tajwidnya maupun dari cara membacanya dengan suara yang indah.

\section{DAFTAR PUSTAKA}

Abdul Rauf, Abdul Aziz. 2004. Kiat Sukses Menjadi Hafizh. Bandung: Syamil

Abdul Rauf, Abdul Aziz. 2015. Pedoman Daurah Al-Qurean: Panduan Ilmu Tajwid Aplikatif. Jakarta: Markaz Al-Qur'an

Abdullah bin Muhammad. 2004. Tafsir Ibnu Katsir, Jilid 8. Bogor: Pustaka Imam Syafie $i$ al-Jauziyyah, Ibnu al-Qoyyim. 1996. ,al „,ilmu fadluhu wa syarfuhu, majmu“ah at-tuhfa anNafais ad-Dauliyyah

al-Sa ${ }^{e e}$ di, Abd al-Rahman. 2000. Taisir al-Karim al-Rahman fi Tafsir Kalam al-Mannan. T.p, Muassasah al-Risalah

Ariffin, Sadek. 2014. Implementation Of Panipati Method On Memorization The Quran In Malaysia: A Study In Tahfiz Institute, ITMAR-2014Full Paper Proceeding/Vol$1,406-413$.

Asyafah, Abas. 2014. The Method Of Tadabur Qurean: What Are The Student Views, Journal International Education Studies, 7(6)

Bakar, Abdul Karim. 2011. Haula at-Tarbiyah wa at-Ta ${ }^{e c}$ lim. Damaskus: Dar al-Qalam Djaali. 2008. Psikologi Pendidikan. Jakarta: Bumi Aksara 
Fatimah, M. 2019. Concept of Islamic Education Curriculum: A Study on Moral Education in Muhammadiyah Boarding School, Klaten, Jurnal Didaktika Religia, 6(2) DOI: 10.30762/didaktika.v6i2.1103.

Fattah, Nanang. 2013. Landasan Manajemen Pendidikan. PT Remaja RosdaKarya, Bandung

G. Zaman, F. K. Afridi and M. Saleem. 2013. Islam and Management Principles: Evidence FromLiterature, Journal of Managerial Sciences, 7(2)

Hashim, A. 2015. Correlation Between StrategyOf Tahfiz Learning Styles And Students Performance In Al-Qur"an Memorization (Hifz), Mediterranean Journal of Social Sciences, 6(2S5)

Lexy, J. Moleong. 2000. Metode Penelitian Kualitatif. Remaja Rosdakarya: Bandung

Majid, A. 2014. Strategi Pembelajaran, Cet. Ke 3. Bandung: PT Remaja Rosdakarya

Mohd Aderi Che Noh, M. A., Hussein, A., Ghni, O. and Suhid, A. 2013. The Study of Quranic Teaching and Learning: A Review in Malaysia and United Kingdom, Middle-East Journal of Scientific Research 15(10): 1338-1344, DOI: 10.5829/idosi.mejsr.2013.15.10.11509

Muhammad al-Ghazali. 1992. Kaifa Nata amal Ma"ea Al-Qurean. Mansurah: Dar al-Wafae

Muhammad Asy-Syintiqi, M. H. 2011. Kiat Mudah Menghafal Al-Qurean. Solo: Gazzamedia

Muhammed Yusuf. 2010. Memorization As A Learning Style: A Balance Approach To Academic Excellence, Oida International Journal Of Sustainable Development, 01(06). Pp. 49-58.

Mulyasa. E. 2006. Kurikulum yang di sempurnakan. Bandung: PT Remaja Rosdakarya

Mustaffa, M., Yusof, M. F., Ghazali, M. Aieikhsan And Sawari, S. S. Md. 2016. Descriptive Qualitative Teaching Method Of Memorization In The Institution Of Tahfiz AlQur'an Wal Qiraat Pulai Condong And The Students ${ }^{\text {ee }}$ Level Of Academic Excellence, Mediterranean Journal of Social Sciences, 7(1) S1, Doi:10.5901/mjss.2016.v7n1s1p79.

Nawaz1, N \& Jahangir, S.F. 2015. Effects of Memorizing Quran by Heart (Hifz) On Later Academic Achievement, Journal of Islamic Studies and Culture, 3(1), pp. 58-64, DOI: 10.15640/jisc.v3n1a8.

Othman, A. 2018. Surayya Abu Bakar, Ahmad Faizuddin, Jama ${ }^{e e}$ ah And Collegial Model In Educational Institutions: Lessons And Principles Learned From Quran And Sunnah, Al-Shajarah, Journal Of Islamic Thought And Civilization Of The International Islamic University Malaysia (Iium)

Sayyid Qutb. 1992. Fi Dilal Al-Qurean. Beirut: Dar al-Shuruq Souad, M., Ramdane, T., Husen, Hayati Nor., Khalid, M., Lide, N., Kassim, A and Suhailawaty, S, Md Sidek. 2018. Muslim students ${ }^{e e}$ perception of western values as presented in english text books: international islamic school Malaysia (secondary) as a case study, al-

Shajarah journal of Islamic thought and civilization of the International Islamic university Malaysia (iium)

Surakhmad, Winarno.1982. Pengantar Interaksi Mengajar-Belajar Dasar dan Teknik Metodelogi Pengajaran. Bandung: Tarsito 
Uno, B. H. \& Mohamad, N. 2011. Belajar dengan Pendekatan PAILKEM. Jakarta: PT Bumi Aksara

Wahbah Zuhaili. 2003. Al-Tafsir Al-Munir, Vol V. Damaskus: Dar al-Fikr

Yahya, S.A.B. 1994. Al-Tibyan fi Adab Hamlah Al-Qur'an, (Damsyik, Beirut. Maktabah Dar Al-Qur'an, al-Muayyad

Yusuf al-Qardawi. 1999. Kaifa Nata "eamal maea Al-Qurean. Kairo: Dar al-Shuruq. 